\title{
Letter to the Editors
}

\section{Birthweight and cytochrome P4503A4/5 activity in obese women}

\section{Ganesh Cherala, ${ }^{1,3}$ Kent Thornburg ${ }^{2} \&$ Alison Edelman ${ }^{3}$}

${ }^{1}$ Department of Pharmacy Practice, College of Pharmacy, Oregon State University/Oregon Health \& Science University, ${ }^{2}$ School of Medicine and ${ }^{3}$ Department of Obstetrics \& Gynecology, Oregon Health \& Science University, Portland, OR, USA

Large interindividual variability in drug pharmacokinetics is a challenge in the delivery of optimal pharmacotherapy. Obesity is a confirmed source of interindividual variability in the activity of cytochrome P4503A4/5 (CYP3A4/5) [1], an important determinant of drug pharmacokinetics. In a recently published study [2], we observed a large interindividual variability in CYP3A4/5 activity within obese women. However, the magnitude of change did not correlate linearly with the magnitude of obesity or the percentage of body fat, leading to speculation that sources other than sex and body mass index are at play. The need for understanding and predicting interindividual variability within these patients is critical given the current obesity epidemic.

In utero growth restriction is strongly correlated to a higher incidence of obesity during adulthood [3]. In utero growth restriction is accompanied by morphological and physiological alterations in various organs [4]. These changes, especially to the liver, may affect drug metabolism during postnatal life, resulting in interindividual variability. We hypothesize that CYP3A4/5 is functionally altered by in utero growth restriction. The objective of this study is to determine whether birthweight, a surrogate marker of in utero growth restriction, is predictive of CYP3A4/5 enzyme activity in obese women.

A randomized, prospective study was conducted at the Oregon Health \& Science University. The Institutional Review Board approved the study protocol, and all subjects provided written informed consent. Thirty-two obese women (18-35 years old; body mass index $\geq 30 \mathrm{~kg} \mathrm{~m}^{-2}$ ) were divided into quartiles based on their self-reported birthweight (in kilograms): (1) $<2.72$; (2) $2.72-3.17$; (3) 3.18-3.63; and (4) $>3.63$. There were no statistical differences in age or body mass index in the four quartiles of women. Venous blood samples were collected via an indwelling catheter at 0 (baseline), $0.25,0.5$, $1,2,4,5,6,12$ and $24 \mathrm{~h}$ following a single $2 \mathrm{mg}$ oral dose of midazolam. Plasma was separated, and aliquots were stored at $-80^{\circ} \mathrm{C}$ prior to analysis. Both bioanalysis and

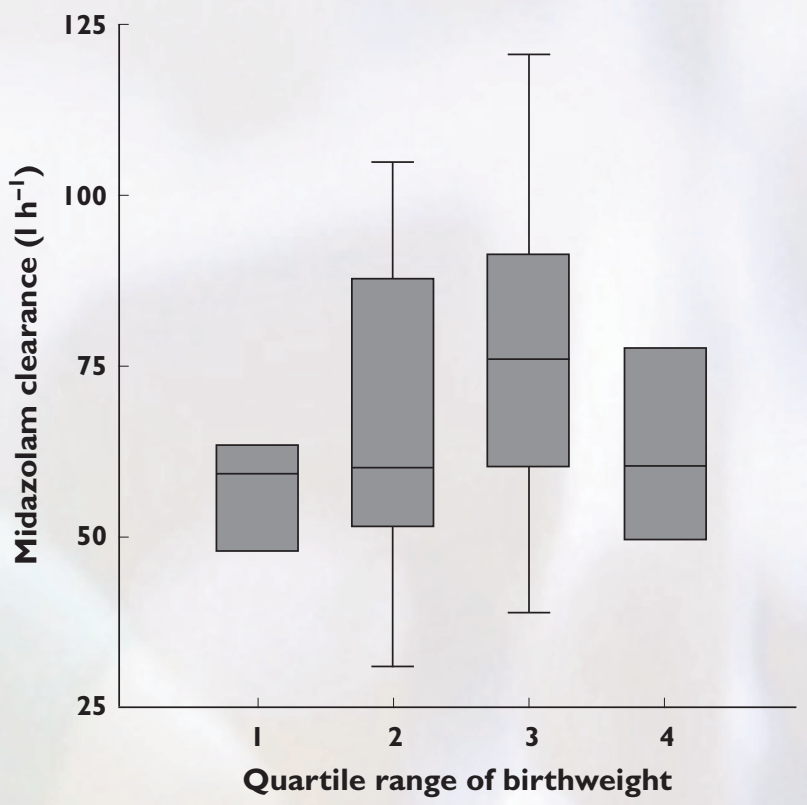

\section{Figure 1}

Effect of birthweight on midazolam clearance. Each box represents 25-75 percentile data, with a line representing the median and whiskers depicting 5-95 percentile data; $n=5-11$. The $95 \%$ confidence intervals (whiskers) were not computed for quartiles 1 and 4 as a result of small sample size

pharmacokinetics analysis were described previously [2]. A one-way ANOVA was used to examine the effect of birthweight on midazolam oral clearance. The relationship between birthweight and oral clearance was also tested using regression analysis.

The CYP3A4/5 activity, measured as midazolam oral clearance, was similar among the four quartiles of birthweight (Figure 1). However, an interesting, inverted $\mathrm{U}$-shaped trend was observed; clearance trended to increase as quartiles of birthweight increased until 
quartile 3 (normal birthweight; 3.18-3.63 kilograms), then the trend reversed as birthweight continued to increase further. In order to confirm the U-shaped trend, clearance was fitted using polynomial regression, which demonstrated a statistically significant third-order polynomial fit to birthweight $(P=0.044)$.

The change in clearance that is related to growth in the womb suggests that the complex determinants of drug disposition are permanently changed by the intrauterine environment. It is striking that the nature of this observed relationship between birthweight and clearance in the present study is similar to those linking birthweight to the incidence of diseases during adulthood $[5,6]$. This similarity is suggestive of the critical role played by an adverse in utero environment in drug pharmacokinetics. Clearance is of critical importance in the therapeutic use of a drug, and our data suggest that part of the biological variation in the clearance is related to historical prenatal growth patterns.

Birthweight is a relatively accessible, no-cost, patientspecific parameter that could be utilized in the optimization of pharmacotherapies. Along with other patientspecific parameters, such as body mass index, age, ethnicity, race, etc, birthweight could serve as useful information to personalize medicine. Although our observation was novel, the small sample size limits our ability to reach definitive conclusions. Further studies with a larger sample size, both sexes and a wider body mass index range are required, along with recorded birthweight, to establish conclusively the relevance of birthweight information in clinical practice.

\section{Competing Interests}

There are no competing interests to declare.

\section{REFERENCES}

1 Spriet I, Meersseman W, de Hoon J, von Winckelmann S, Wilmer A, Willems L. Mini-series: Il. Clinical aspects. Clinically relevant CYP450-mediated drug interactions in the ICU. Intensive Care Med 2009; 35: 603-12.

2 Edelman A, Munar M, Elman MR, Koop D, Cherala G. Effect of Ethinyl estradiol/ Levonorgestrel combined oral contraceptive on the activity of Cytochrome P4503A in obese women. Br J Clin Pharmacol 2012; 'Accepted Article' doi: 10.1111/j.1365-2125.2012.04209.x.

3 Godfrey KM, Barker DJ. Fetal programming and adult health. Public Health Nutr 2001; 4: 611-24.

4 McMillen IC, Robinson JS. Developmental origins of the metabolic syndrome: prediction, plasticity, and programming. Physiol Rev 2005; 85: 571-633.

5 Gunnarsdottir I, Birgisdottir BE, Benediktsson R, Gudnason V, Thorsdottir I. Association between size at birth, truncal fat and obesity in adult life and its contribution to blood pressure and coronary heart disease; study in a high birth weight population. Eur J Clin Nutr 2004; 58: 812-8.

6 Gluckman PD, Hanson MA, Cooper C, Thornburg KL. Effect of in utero and early-life conditions on adult health and disease. N Engl J Med 2008; 359: 61-73.

\section{RECEIVED}

12 March 2012

ACCEPTED

15 April 2012

\section{ACCEPTED ARTICLE PUBLISHED ONLINE 25 April 2012}

\section{CORRESPONDENCE}

Ganesh Cherala, PhD, 3303 SW Bond Avenue, CH12C, Portland, OR 97239, USA.

Tel.: +1 5034180447

Fax: +1 5034948797

E-mail: cheralag@ohsu.edu 